Cite this: Metallomics, 2013, 5, 1584

Received 26th August 2013, Accepted 10th October 2013

DOI: $10.1039 / c 3 m t 00232 b$

www.rsc.org/metallomics

\title{
Aluminium speciation and internal detoxification mechanisms in plants: where do we stand?
}

\author{
Tomás Grevenstuk and Anabela Romano*
}

\begin{abstract}
Aluminium (Al) typically has a deleterious impact on plant growth and development but some plants can accumulate otherwise toxic concentrations of this metal by deploying internal detoxification mechanisms (tolerance mechanisms). Although there are scattered reports concerning the regulation of Al uptake, transport and storage in metabolically innocuous forms, the overall picture remains incomplete and there are no accounts of a general overview of Al tolerance mechanisms. This review aims to compile the current knowledge on the physiological basis of Al tolerance and speculate on possible underlying molecular mechanisms regarding the uptake of $\mathrm{Al}$, speciation in internal organs, transport to upper organs and storage in non-vital structures. Given the difficulties in detecting and studying the speciation of $\mathrm{Al}$, special attention will be given to the approaches used so far and new developments that allow greater sensitivity and accuracy in uncovering the fate of Al in planta.
\end{abstract}

\section{Introduction}

Aluminium (Al) toxicity is one of the most serious limitations to plant growth in acidic soils. Most $\mathrm{Al}$ is fixed in minerals or bound to particle surfaces as oxides and aluminosilicates, which are harmless to plants. However, $\mathrm{Al}$ in acidic soils is solubilized as the trivalent cation $\mathrm{Al}^{3+}$ (Fig. 1A). The exact mechanisms behind Al toxicity are still not fully understood, yet most evidence suggests that $\mathrm{Al}^{3+}$ is responsible for the inhibition of root elongation, hindering subsequently the uptake of water and nutrients. The topic of Al toxicity falls

IBB-CGB, Faculty of Sciences and Technology, University of Algarve, Campus de Gambelas, 8005-139 Faro, Portugal. E-mail: tgrevens@ualg.pt, aromano@ualg.pt; Fax: +351 289 818419; Tel: +351 289800910 outside the scope of this work and extensive reviews can be found elsewhere. ${ }^{1}$

Approximately $30 \%$ of the world's total ice-free land has a $\mathrm{pH}<5.5^{2}$ and because $\mathrm{Al}$ is the third most abundant element in the earth's crust it is clear that crop productivity is substantially reduced by Al toxicity. However, some plants thrive in soils with high concentrations of free $\mathrm{Al}$ and can be grouped according to the strategy used to counteract Al stress. Al-excluding plants prevent $\mathrm{Al}$ from entering the symplasm (resistance), whereas Al-accumulating plants store $\mathrm{Al}$ in their above-ground tissues without signs of toxicity (tolerance). Unfortunately, the terminologies "tolerance" and "resistance" are often used ambiguously. In this review, tolerant plants are considered exclusively those that deploy internal mechanisms

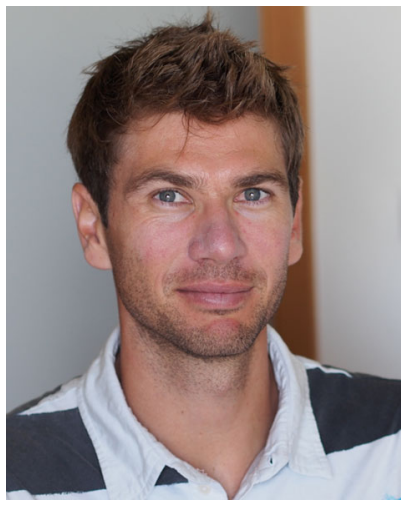

Tomás Grevenstuk is a postdoctoral research scientist at the Plant Biotechnology Laboratory, University of Algarve. His current research interests focus on $\mathrm{Al}$ detoxification mechanisms in tolerant plants with a particular interest in $\mathrm{Al}$ speciation and the effects of aluminium stress on the plants' metabolome.

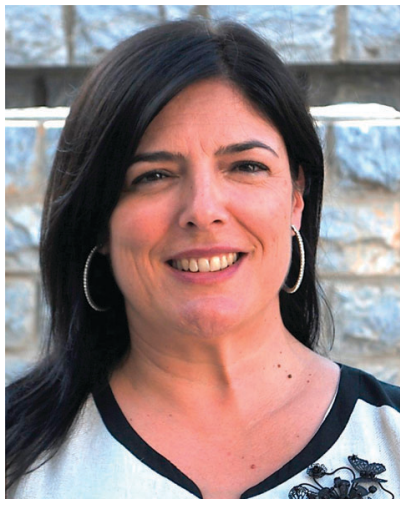

Anabela Romano is an associate professor and head of the Laboratory of Plant Biotechnology at the University of Algarve, Portugal. Her research interest focuses in plant's response to abiotic stress and tolerance mechanisms. 


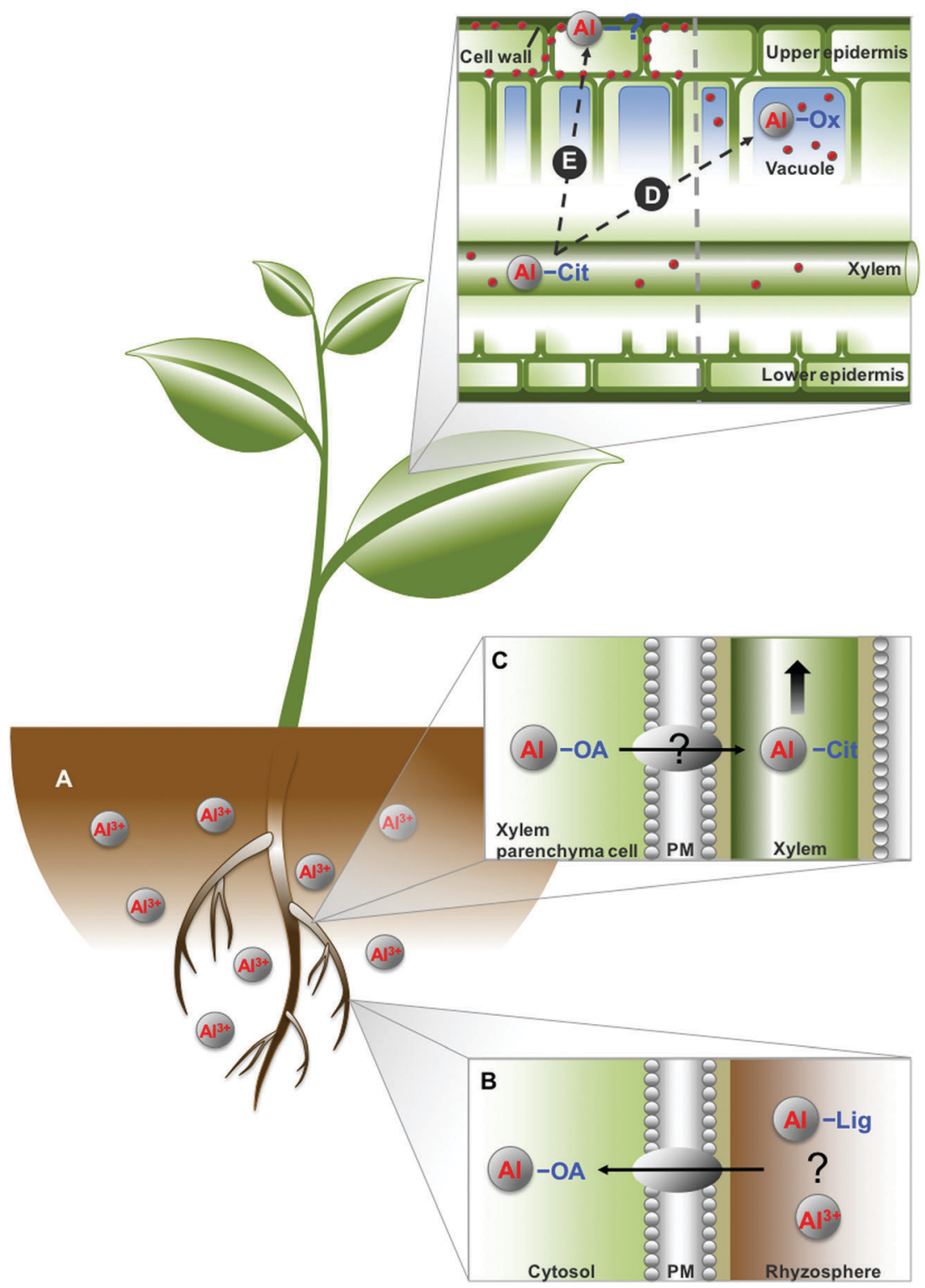

Fig. 1 General overview of Al uptake, transport and storage in tolerant plants. (A) In acid soils Al exists as soluble Al ${ }^{3+}$ ions, tolerant plants take up Al and store it in innocuous forms in upper organs. These mechanisms are beneficial possibly by minimizing contact of the toxic $\mathrm{Al}^{3+}$ ion with sensitive zones at the root apex. (B) Specific Al transport proteins have not been identified in tolerant plants and it is unclear whether $\mathrm{Al}$ is taken up as $\mathrm{Al}{ }^{3+}$ or complexed by ligands. Once $\mathrm{Al}$ enters the root cytosol it is complexed by organic acids. Oxalate-Al complexes have been detected in roots of buckwheat, tea and M. malabathricum and citrate-Al complexes in roots of $P$. almogravensis. (C) The xylem flow transports Al, complexed by citrate, from roots to upper organs. It is not known where Al is loaded into the xylem or how this process is mediated. At the leaves, Al-citrate complexes are unloaded from xylem and directed to metabolically less active structures. In buckwheat and in M. malabathricum leaves $\mathrm{Al}$ is stored in vacuoles as Al-oxalate complexes (D) while in tea $\mathrm{Al}$ is sequestered at the cell wall of upper epidermal cells (E). Al-catechin complexes have been detected in tea leaves, however catechins are mostly found in vacuoles of mesophyll cells so it is uncertain how Al is complexed at the cell wall. Abbreviations: Lig, unknown ligand; OA, organic acid; Cit, citrate; Ox, oxalate.

to detoxify $\mathrm{Al}$ and resistant plants those that exclude $\mathrm{Al}$. These mechanisms are not mutually exclusive, buckwheat (Fagopyrum esculentum) and rice (Oryza sativa) for example benefit from both mechanisms. ${ }^{3}$ Rice is the most resistant cereal crop to $\mathrm{Al}$ and is essentially an Al-excluder. But, rice plants do take up Al actively (reaching concentrations in root cell sap higher than those found in culture solution $)^{4}$ and at the cellular level $\mathrm{Al}$ is directed to vacuoles by specific transporters. ${ }^{5}$ Because some of the molecular mechanisms behind these efficient internal detoxification steps have been uncovered recently in rice, these results will be discussed as they may provide new leads concerning the internal detoxification of $\mathrm{Al}$ in tolerant plants. In crops the most prevalent strategy to cope with $\mathrm{Al}$ stress is exclusion and therefore the corresponding resistance mechanisms are better understood. In short, resistant plants prevent the import of $\mathrm{Al}$ into the cytosol by releasing organic acid (OA) anions from the root system to chelate and immobilize $\mathrm{Al}$ in the rhizosphere. This review focuses exclusively on the current 
knowledge of $\mathrm{Al}$ tolerance mechanisms and readers interested in the physiology, molecular mechanisms and the genetic basis of $\mathrm{Al}$ resistance are referred to the following comprehensive reviews: ${ }^{1 c, 6}$

Less is known about the tolerance mechanisms in Al-accumulating plants but it is clear that such plants must be able to: (1) absorb Al via the roots; (2) bind Al with safe ligands to form stable complexes; (3) transport these complexes to aboveground organs; and (4) store them in an innocuous and metabolically-inactive form. Several mechanisms have been reported, including chelation with organic ligands in the cytosol and compartmentalization in specific plant organs, but there has been no comprehensive discussion of these findings. In this review, we discuss the latest data relevant to Al-tolerance mechanisms, including the internal speciation of $\mathrm{Al}$ and the uptake via the roots to sequestration in the leaves, focusing on the challenges and new leads that need to be pursued. A better understanding of Al-tolerance at the physiological level is important to characterize the underlying molecular and genetic mechanisms.

\section{The speciation of aluminium in plants}

Al cannot exist intracellularly in its free form and is necessarily bound by ligands. However, the speciation of $\mathrm{Al}$ in biological samples has been hampered by the technical constraints limiting the separation and identification of $\mathrm{Al}$ complexes. ${ }^{7}$ The lack of a suitable isotope, the relatively low sensitivity of nuclear magnetic resonance (NMR) and X-ray detection based techniques and the unstable nature of Al-complexes, which can suffer changes in speciation during extraction and analytical procedures, are the major hurdles for accurate speciation of $\mathrm{Al}$ in plants.

\section{1. ${ }^{27}$ Al nuclear magnetic resonance detection}

The large body of knowledge concerning the speciation of $\mathrm{Al}$ in plants has almost exclusively been provided by ${ }^{27} \mathrm{Al} \mathrm{NMR}$ spectroscopy. This approach does not require sample preparation or chromatographic separation and can provide structural information about $\mathrm{Al}$ complexes directly from intact samples. Because ${ }^{27} \mathrm{Al}$ is an isotope with a non-zero spin $(5 / 2)$ it can be detected by NMR spectroscopy using specific probes, and $\mathrm{Al}$ complexes can be identified by comparing their characteristic chemical shifts to those of standards. Two main conclusions can be drawn from these experiments: (1) OAs are the major ligands for $\mathrm{Al}$ in all species studied thus far, and therefore play a key role in the internal Al-detoxification mechanisms of plants; and (2) Al-detoxification mechanisms in plants are highly complex.

In buckwheat, $\mathrm{Al}$ is bound to oxalate ions in the roots, ${ }^{8}$ to citrate ions in the xylem ${ }^{9}$ and again to oxalate ions in the leaves (Fig. 2) ${ }^{10}$ indicating that ligand exchanges must occur when $\mathrm{Al}$ is transported from the root symplasm to the xylem, and from the xylem to the leaves. Similar ligand exchange mechanisms have been reported in Melastoma malabathricum and tea (Camellia sinensis) where again $\mathrm{Al}$ is bound to oxalate ions in the roots ${ }^{11}$ and to citrate ions in the xylem. ${ }^{12}$ In M. malabathricum leaves $\mathrm{Al}$ is found both as monomeric $\mathrm{Al}$ as well as oxalate complexes ${ }^{13}$ and in tea leaves $\mathrm{Al}$ forms complexes with catechins (Fig. 2). ${ }^{14}$ However, a different study indicated that the resonances in the spectra of tea infusions could not be assigned to Al complexes with major polyphenolic constituents and that the detected peaks are attributable to Al-oxalate complexes. ${ }^{15}$ Several different complexes with the same ligand can coexist in the same organ: ${ }^{27} \mathrm{Al}$ NMR spectra obtained from $M$. malabathricum indicated the presence of Al-oxalate, Al-(oxalate) $)_{2}$ and $\mathrm{Al}-(\text { oxalate })_{3}$ in intact leaves, ${ }^{13}$ as well as Al-(oxalate) $)_{2}$ and $\mathrm{Al}-(\text { oxalate })_{3}$ in roots, ${ }^{11 b}$ without a clear

1.

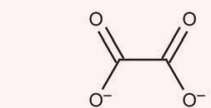

2.<smiles>O=C([O-])CC(O)(CC(=O)[O-])C(=O)[O-]</smiles>

3.

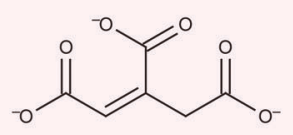

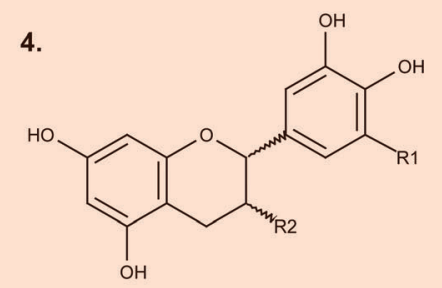



6.

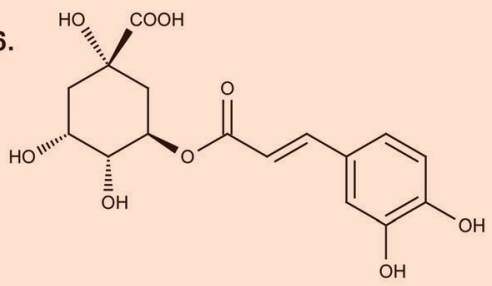

Organic acids

Phenolic compounds

Fig. 2 Ligands involved in Al complexation in tolerant plants: oxalate (1), citrate (2), aconitate (3), catechins (4), delphinidin-3-O-glucoside (5) and the co-pigment 3-O-caffeoylquinic acid (6). 
indication of how they are formed or their relative abundance. Since the complexes form spontaneously when $\mathrm{Al}$ and oxalate or citrate are mixed in solution it is likely that the $\mathrm{OA}$ : $\mathrm{Al}$ ratio and the respective thermodynamic favorability at physiological $\mathrm{pH}$ determine the concentration of each individual complex. Accordingly, buckwheat leaves produce oxalate in a large excess compared to $\mathrm{Al}(25: 1)$ and the $\mathrm{Al}$-(oxalate) $)_{3}$ complex is formed preferentially. ${ }^{10}$ In $M$. malabathricum leaves the molar ratio between oxalate and $\mathrm{Al}$ is $2: 1$, and the $\mathrm{Al}$-oxalate complex is thus more abundant. ${ }^{13}$

Another interesting aspect is that $\mathrm{Al}$ speciation in buckwheat is dependent on the internal metal concentration. That is, $\mathrm{Al}$ is preferentially bound to oxalate unless the oxalate concentration is limiting. In this case Al-citrate complexes can be found in leaves too, possibly because they are not converted to $\mathrm{Al}$-oxalate after transfer from the xylem to the leaf symplasm. ${ }^{16}$ From a biological perspective the plants benefit from Al binding by oxalate, since the resulting complexes have higher stability constants than the Al-citrate complex.

The accumulation of $\mathrm{Al}$ in Hydrangea macrophylla (Thunb.) "ser." is well documented and has the unusual characteristic that it can be detected visually. The exact mechanism is not understood yet but it is known that $\mathrm{Al}$ forms a complex with delphinidin-3-glucoside (Fig. 2), an anthocyanin that normally confers a red color on the sepals, converting it to the blue quinoidal-base anionic form. ${ }^{17}$ The co-pigment 3-O-caffeoylquinic acid (Fig. 2) seems to be required to solubilize the Al-delphinidin complex. The blue color of $H$. macrophylla flowers becomes more intense as $\mathrm{Al}$ accumulates, making these plants natural indicators of soil acidity because $\mathrm{Al}$ is only solubilized in acidic soils. It would be interesting to analyze the sepals of Al-treated plants by ${ }^{27} \mathrm{Al}$ NMR spectroscopy to determine the chemical environment of the Al nucleus, as this has not been reported. The $\mathrm{Al}$ in $H$. macrophylla leaves is detoxified by forming complexes with citrate in a $1: 1$ molar ratio ${ }^{18}$ yet it is unclear in which form $\mathrm{Al}$ is transported and taken up at the roots.

The greatest drawback of NMR spectroscopy as a detection technique is that it is relatively insensitive. For this reason, speciation has been investigated predominantly in hyperaccumulators, where $\mathrm{Al}$ complexes are often present at concentrations $>2 \mathrm{mM}$ and direct identification can be achieved. Another limitation of ${ }^{27} \mathrm{Al} \mathrm{NMR}$ spectroscopy is that the resulting data reflect the immediate chemical neighborhood of the Al nucleus, and therefore cannot distinguish complexes comprising larger ligands with similar chemical shift values. The Al nucleus is quadrupolar and yields broad signals over a wide chemical shift range, reducing the resolution of this technique even further. ${ }^{19}$ More recent ${ }^{1} \mathrm{H}-{ }^{27} \mathrm{Al}$ heteronuclear experiments ${ }^{20}$ may provide better discrimination and thus more accurate structural data in these cases.

\subsection{Electrospray ionization-mass spectrometry detection}

The few reports on Al speciation studies based on mass spectrometry after electrospray ionization (ESI-MS) reflect its inherent technical challenges. However, ESI-MS is a useful alternative to ${ }^{27} \mathrm{Al} \mathrm{NMR}$ when the concentration of $\mathrm{Al}$ in samples is limiting, because it can routinely deliver structural information on metal complexes at $\mu \mathrm{M}$ concentrations without prior information. ${ }^{21}$ The transition from solution to the gas phase by ESI is particularly gentle, maintaining solution phase speciation to a large extent. Therefore, the dissociation of metal complexes is less likely, making it possible to measure and obtain information on intact complexes. Because low collision energies are applied, the ionization process generally produces singly-charged species with high mass resolution, yielding simple mass spectra that facilitate assignment. ${ }^{22}$ ESI-MS also provides information on the stoichiometry of complex formation making it perhaps one of the most powerful tools for metal complex analysis.

Biological samples are too complex for direct infusion or flow injection, so chromatographic separation is needed under conditions that prevent dissociation. Also, because $\mathrm{Al}$ is a monoisotopic element and $\mathrm{Al}$ species cannot be distinguished in mass spectra (unlike elements such as Ni or Fe which have characteristic isotopic patterns) an elemental detection technique must be used in parallel. MS detection after complete ionization using an inductively coupled plasma (ICP) discharge can indicate the retention times of $\mathrm{Al}$ complexes and allow further investigation by MS. An approach based on anion and cation exchange chromatography followed by ICP-atomic emission spectrometry showed that the major Al-binding ligands were citrate and aconitate (Fig. 2) in Sempervivum tectorum and Sansevieria trifasciata leaves, ${ }^{23}$ two plant species not commonly known for their Al-accumulating behavior. Al-containing fractions of plant sap samples obtained by strong anion or cation exchange chromatography were analyzed off-line by ESI-MS. The identity of the Al complexes was confirmed by comparing the retention times with those of synthetic standards and by identifying the molecular ions of citrate and aconitate in the MS spectra of collected fractions. However, intact complexes were not detected, possibly because the ionization conditions were harsh enough to cause in-source dissociation. Also, the possibility that $\mathrm{Al}$ can be redistributed between ligands after tissue disruption has to be considered.

Technical improvements that have made detection more robust include online ICP-MS measurements that avoid tedious Al quantification procedures in fractionated samples, and the simultaneous monitoring of signals from elements like Fe and Mn with characteristic isotopic patterns. This information allows determining whether such elements co-elute with $\mathrm{Al}$ complexes due to competition for the same ligand, helping to localize $\mathrm{Al}$ complexes in mass spectra. Although ion exchange chromatography is widely used for the separation of synthetic OA-Al complexes, the resolving capacity is not sufficient to separate all complexes and the typical high-salt buffer composition can suppress ionization. ${ }^{21}$ The limited interaction between metal complexes and size-exclusion chromatography (SEC) resins allows the separation of $\mathrm{Al}$ complexes from matrix components that suppress ionization, while minimizing interactions that may cause complex dissociation. ${ }^{22}$ However, metal adsorption to residual $\mathrm{COOH}$ and $\mathrm{OH}$ groups on chromatography resins can interfere in speciation studies and this must be taken into account. ${ }^{21}$ The $\mathrm{OA}-\mathrm{Al}$ complexes identified thus 
far are highly polar, so hydrophilic interaction chromatography (HILIC) is another useful method for the separation of $\mathrm{Al}$ complexes prior to ESI-MS. The polar resins guarantee strong retention of the complexes and the corresponding buffers are compatible with ESI. ${ }^{24}$

An integrated MS approach based on HILIC and SEC liquid chromatography followed by parallel ICP-MS and ESI-MS measurements using the Fe signal as an internal tracer in MS spectra proved successful in the identification of a tri-Al-tricitrate complex $\left(\mathrm{Al}_{3}-\right.$ citrate $\left._{3}\right)$ in root and leaf extracts of the hyperaccumulator Plantago almogravensis without any prior information. ${ }^{25}$ Apart from $\mathrm{Al}_{3}$-citrate ${ }_{3}$, two other yet unidentified $\mathrm{Al}$-citrate complexes were detected and their relative concentration was influenced by internal $\mathrm{Al}$ concentration. The theoretical speciation diagrams of citrate and $\mathrm{Al}$ solutions support the occurrence of three distinct complexes at physiological $\mathrm{pH},{ }^{26}$ and accordingly the two unidentified complexes could correspond to Al-citrate and Al-citrate $e_{2}$. The calculated stability constants for the different Al-citrate complexes expected to occur in $P$. almogravensis are very discrepant. The relative concentration of these complexes has consequences regarding the protection capacity of the formed complexes, highlighting the importance of knowing the accurate speciation of $\mathrm{Al}$. The developed methodology surpasses the problems of complex dissociation during chromatography and lack of sensitivity, and can be used to study the speciation of $\mathrm{Al}$ at biologically relevant concentrations and in less tolerant plants.

\subsection{Organic acids and internal Al detoxification}

Other classes of metal ligands such as phytochelatins, metallothioneins and amino acids (histidine) are involved in the detoxification of $\mathrm{Ni}, \mathrm{Cd}$ and $\mathrm{Zn}$, but there is a fundamental relationship between OAs and $\mathrm{Al}$ tolerance as highlighted above. The minor importance of these ligands in terms of $\mathrm{Al}$ tolerance may reflect the status of $\mathrm{Al}$ as a hard cation with a higher affinity for strong electronegative structures such as carboxyl, hydroxyl and carbonyl groups, in comparison to amines and sulfhydryl groups when these are not part of multidendate ligands. ${ }^{27}$ In fact, it would be interesting to re-analyze the speciation of $\mathrm{Al}$ in tea leaves using more recent ESI-MS strategies. ${ }^{27} \mathrm{Al}$ NMR spectroscopy can only demonstrate that the Al nucleus is most likely in the direct neighborhood of a catechol group, but cannot identify the exact ligand because structural differences are not reported in the NMR spectrum.

High stability constants have been reported for Al-OA complexes in Al-accumulating plants and they are not phytotoxic, ${ }^{8,18}$ indicating that $\mathrm{Al}-\mathrm{OA}$ complexes are important features of internal Al detoxification mechanisms. Ryan and Delhaize $^{3 b}$ discuss the possibility that $\mathrm{Al}$ resistance and tolerance mechanisms based on OAs may have evolved independently several times due to the ubiquitous nature of these metabolites and the low metabolic investment that is required to synthesize them. Indeed, a metabolically inexpensive mechanism is necessary when one considers that $\mathrm{Al}^{3+}$ toxicity is one of the most frequent challenges to normal plant development.

\section{The uptake of aluminium}

\subsection{In which form is Al taken up?}

The uptake of $\mathrm{Al}$ from the soil is poorly understood and to date there has been no conclusive evidence on how $\mathrm{Al}$ is taken up in tolerant plants (Fig. 1B). Ma et al. ${ }^{3 a}$ proposed that $\mathrm{Al}$ is taken up as $\mathrm{Al}^{3+}$, following the rationale that there is a large electrochemical gradient favoring $\mathrm{Al}$ transfer across the plasma membrane. This gradient is perpetuated because $\mathrm{Al}$ as any metal cannot exist as a free ion at significant concentrations in the cytosol and is immediately chelated. ${ }^{28}$ Much of the work reported by Ma and colleagues was based on buckwheat, and it would seem conflicting if $\mathrm{Al}$ were to be taken up preferentially bound to organic molecules, since typical Al-exclusion mechanisms are based precisely on the exudation of OAs that chelate $\mathrm{Al}$ externally. However, opinions on this subject are divergent and it has been proposed that formation of an OA-Al complex is a prerequisite for transport into symplast in buckwheat. ${ }^{29}$ When Chinese cabbage (Brassica rapa ssp. pekinensis) is provided with $\mathrm{Al}$ in the form of $\mathrm{Al}$-citrate or Al-malate, it is taken up and loaded into xylem directly without chemical modification, albeit at slower rates than free $\mathrm{Al}^{30}$ It was proposed that in tea $\mathrm{Al}$ is taken up as $\mathrm{AlF}_{2}{ }^{+}$or $\mathrm{AlF}^{2+}, 31$ but experimental data did not support this hypothesis. ${ }^{12 a} \mathrm{Al}$ uptake is reduced in M. malabathricum roots exposed to a nutrient-free solution containing $\mathrm{Al},{ }^{11 b}$ but independent experiments ruled out the possibility that $\mathrm{Pi}, \mathrm{NO}_{3}{ }^{-}$or $\mathrm{SO}_{4}{ }^{2-}$ could act as counteranions necessary for uptake. ${ }^{13,32}$ In $P$. almogravensis leaves $\mathrm{Al}$ is complexed by citrate, however, when the root system is excised it seems to be taken up bound to phosphate, one of the most predominant $\mathrm{Al}$ species in the nutrient solution. ${ }^{25}$ The secretion of citrate in response to $\mathrm{Al}$ is not significant and the concentration of the $\mathrm{OA}$ in shoots is sufficient to complex $\mathrm{Al}$ in these plants. ${ }^{33}$ This suggests that the complexation of $\mathrm{Al}$ by citrate in $P$. almogravensis is dependent on $\mathrm{Al}$ being taken up in its free form. The only Al-transporter identified so far in plants seems to transport $\mathrm{Al}^{3+}$. ${ }^{4}$ However, because only one complexing agent and one ratio of citrate to $\mathrm{Al}^{3+}$ were tested the possibility that a complexed form of $\mathrm{Al}$ is transported cannot be ruled out. Therefore it appears that $\mathrm{Al}$ can be taken up either as a free ion or as complexes with organic or inorganic ligands, and that the transport proteins that transfer $\mathrm{Al}$ across the plasma membrane are not universal.

\subsection{How does Al permeate the plasma membrane?}

To date it is not known if tolerant plants take Al up using specific transporters. The most common strategy to identify new families of metal transporters is the complementation of mutant yeast strains defective for the uptake of a specific metal with a plant cDNA expression library to see if the phenotype can be rescued. This approach has identified transporters for Fe, $\mathrm{Zn}$ and $\mathrm{Mn} .{ }^{34}$ The ionic radius is the most important predictive parameter relating to the biological behavior of metal ions, and the ionic radii of iron and magnesium are closest to $\mathrm{Al}$. It was therefore proposed that $\mathrm{Al}$ could be taken up by co-transport with iron and magnesium. ${ }^{1 b}$ However, promiscuous 
transporters of this nature have not been identified. Also, one major constraint to this co-transport is that $\mathrm{Al}^{3+}$ would have to permeate transport proteins specific for divalent metals. Some grasses, however, can take up $\mathrm{Fe}$ in its +3 oxidation state by releasing ligands called siderophores from the roots, which are subsequently internalized. ${ }^{34}$ While siderophores have been reported to mediate $\mathrm{Al}$ uptake in bacteria, ${ }^{35}$ there are no indications that it is a relevant uptake mechanism in plants.

$\mathrm{Al}$ is not essential for normal plant growth so it could be expected that there are no specific transporters for this metal and that $\mathrm{Al}$ entering the root cytosol is co-transported with essential ions. However, a specific Al transporter was recently discovered in rice and named Nrat1 (Nramp aluminium transporter 1). The protein is located on the plasma membrane of root cells (except epidermal cells) and exclusively $\mathrm{Al}$ induces the corresponding gene. ${ }^{4}$ Nrat1 knockout rice lines generated by retrotransposon insertion confirmed that Nrat1 is necessary for $\mathrm{Al}$ uptake and that in its absence $\mathrm{Al}$ accumulates at the cell wall. This breakthrough shows that Al uptake is mediated by specific transport proteins. Recently, a mutant rice line lacking a vacuolar Al transporter was shown to be just as susceptible to Al when the Nrat1 gene was silenced, suggesting that other transporters in addition to Nrat1 are involved in the uptake of $\mathrm{Al}$ in rice. ${ }^{5}$ Thus far, it is not known if genes homologous to Nrat1 are responsible for the uptake of $\mathrm{Al}$ in tolerant plants.

Information on the dynamics of $\mathrm{Al}$ transport across the plasma membrane in tolerant plants is still lacking and one of the main hurdles is discriminating apoplasmic and symplasmic Al, because of its low abundance and high affinity for cell wall components. The first direct quantitative measurement of Al transport across the plasma membrane was reported by Taylor et al. ${ }^{36}$ using an innovative approach involving accelerated MS to measure the ${ }^{26} \mathrm{Al}$ isotope as a tracer with enough sensitivity to measure the transport of Al into individual cells. The authors used Chara corallina intermodal cells, which do not internalize Al significantly, but the model does provide important information on the Al-permeability of plant plasma membranes and its sensitivity to $\mathrm{pH}$, speciation and metabolic inhibitors. A similar approach would provide valuable information on the transport of $\mathrm{Al}$ in tolerant plants.

\subsection{Site of Al uptake}

The site of Al uptake on the root surface has been a matter of debate. Ma and Hiradate ${ }^{9}$ suggested that the mature elongation zone above the root apex in buckwheat would be the most likely uptake site because oxalic acid is secreted in the greatest amounts from the apex. The Al concentration declines from the apical to the basal zone of the roots in many species. ${ }^{37}$ This gradient is not exclusive for Al-accumulators and cannot be considered an indication of higher accumulation at the root apex on its own. It is most likely related to a higher concentration of negatively-charged pectin at the root apex, for which the $\mathrm{Al}^{3+}$ cation has great affinity. ${ }^{38}$ However, Klug et al. ${ }^{39}$ found that in buckwheat the highest ratio of symplastic $\mathrm{Al}$ to total $\mathrm{Al}$ is found at the root apex, suggesting that this is the most active uptake site.

\section{Xylem loading and aluminium translocation}

Most plants growing on acidic soils accumulate large amounts of $\mathrm{Al}$ at the roots, but only a few species translocate the metal to the shoots. It has been proposed that the Casparian strip in the endodermis, the negatively-charged environment of the Donnan free space in the root-cell apoplasm and the low permeability of the plasma membrane could all present barriers to the diffusion of $\mathrm{Al}^{9}{ }^{9}$ Detailed studies of the structure and composition of the cell wall and the plasma membrane in plants that do or do not translocate $\mathrm{Al}$ may provide insight into the mechanisms responsible for transport and determine whether specialized carriers or channels are involved. According to Ma and Hiradate ${ }^{9}$ the near-neutral $\mathrm{pH}$ of the cytoplasm could also reduce translocation because $\mathrm{Al}$ has a low solubility at this $\mathrm{pH}$. However, a consistently low cytosolic pH has not been observed in Al-accumulators.

Three transport pathways may be involved in Al mobilization: apoplastic transport in the cortical cell walls, symplastic transport and xylem transport. ${ }^{29} \mathrm{Al}$ has been detected in the xylem of the three most widely studied hyperaccumulators (buckwheat, tea and M. malabathricum) and is usually bound to citrate in the xylem rather than oxalate (as in the root cytosol), ${ }^{9,12}$ suggesting that this is a major Al transport route (Fig. 1C). The reason for ligand exchange is unclear but it may help to prevent the formation of calcium oxalate precipitates, given that calcium is more abundant in the xylem than in cytosol. ${ }^{9}$ The site of ligand exchange and the specific location and the mechanism of loading into the central xylem vessels have not been characterized in detail but they are not uniform along the root axis. In buckwheat the subapical 10-20 $\mathrm{mm}$ root segment is the main site of xylem loading. ${ }^{29}$ The contribution of apoplastic transport to $\mathrm{Al}$ translocation is probably negligible at least in buckwheat because $\mathrm{Al}$ transport is unidirectional from the apex to basal regions of the root system whereas diffusion in the apoplast is typically undirected. ${ }^{29}$

The loading of iron into xylem is poorly understood. Only recently has a candidate for the protein that accomplishes this step been identified. ${ }^{40}$ It is well accepted that iron is complexed by citrate in xylem, but it is not known if these complexes are formed at the xylem or prior to xylem loading. If iron is transported as a citrate complex it has to be determined whether $\mathrm{Al}$ can be loaded into the xylem by iron transporters, considering that Al competes with iron for the same citrate complexes. ${ }^{25}$ The regulation of $\mathrm{Al}$ translocation to the upper organs is not understood in detail, but in M. malabathricum roots the activity of citrate synthase increases in response to $\mathrm{Al}$ exposure, thus providing more citrates for efficient Al translocation. ${ }^{32 a}$ Interestingly, the split-root pot experiments used in the work cited above showed that when $\mathrm{Al}$ was applied to only one compartment, citrate synthase activity also increased in the compartment without $\mathrm{Al}$, indicating that the enzyme is stimulated by an unknown yet diffusible factor that is transported across the root system. In buckwheat, the concentration of citric acid is not affected by treatment with $\mathrm{Al} .^{9}$ 
Indeed, little is known about the dynamics of $\mathrm{Al}$ translocation from the roots to the upper organs, which would require real-time analysis in living plants. Despite its relatively low resolution, NMR spectroscopy is one of the few techniques that can resolve static and dynamic parameters concerning the transport of water and specific elements or metabolites in a non-destructive and non-invasive manner. Therefore it can help identify transport structures and measure the Al transfer rate in the context of overall plant water relations. ${ }^{41}$ The ${ }^{27} \mathrm{Al}$ nucleus can be tracked and quantified directly and, unlike other metals, the measurements are independent of relaxation time effects on protons caused by paramagnetic solutes. ${ }^{42}$ Magnetic resonance imaging was used to measure the uptake of lithium and the concentration of lithium along the stem in real time, ${ }^{43}$ but the same method has not yet been used to study Al transport even though the Al nucleus is amenable to this technique.

\section{Subcellular localization and aluminium sequestration}

In accumulating plants, high (normally toxic) concentrations of $\mathrm{Al}$ are found in aboveground tissues, indicating the presence of mechanisms to prevent contact between free $\mathrm{Al}$ and essential biochemical processes. It seems that $\mathrm{Al}$ is either sequestered in the vacuole or the cell wall, depending on the plant species.

\subsection{Vacuolar sequestration}

In protoplasts and vacuoles isolated from buckwheat leaves over $80 \%$ of total $\mathrm{Al}$ had accumulated in the vacuoles. ${ }^{44}{ }^{27} \mathrm{Al}$ NMR spectroscopy indicated that $\mathrm{Al}$ was present as a 1:3 oxalate complex, ${ }^{10}$ the same chemical form present in intact leaves (Fig. 1D). Because most important biochemical processes occur in the cytoplasm, the storage of $\mathrm{Al}$ in an innocuous form within the vacuole may help buckwheat plants to accumulate large amounts of $\mathrm{Al}$ without compromising normal development. The vacuole is also the main site of intracellular metal sequestration in the zinc ( $\mathrm{Zn}$ ) and nickel (Ni) hyperaccumulator Thlaspi caerulescens J. and C. Presl. ${ }^{45}$ In fact, the efficiency of vacuolar sequestration seems to determine the relative tolerance to Ni accumulation in different Thlaspi species. ${ }^{45 a}$

Little information is available on the intracellular transport of $\mathrm{Al}$ in accumulating plants, however some details can be retrieved from studies in other plants. The work conducted on C. corallina cells showed that Al that was not accumulated at the cell wall and was detected in the tonoplast (less than 1\%) was directed to the vacuole. ${ }^{36}$ Although transport across the plasma membrane was almost immediate, Al was only detected in the vacuole from 30 min onwards, suggesting that either the accumulation of $\mathrm{Al}$ or activation of specific transporters is required to initiate sequestration into the vacuole. ${ }^{36}$ In rice, a half-size $\mathrm{ABC}$ transporter encoded by the OsALS1 gene and localized in the tonoplast is responsible for the sequestration of $\mathrm{Al}$ into vacuoles. ${ }^{5}$ More $\mathrm{Al}$ was found in the cytosol and the nucleus of the mutant line compared to wild type plants, confirming that OSALS1 intervenes in the transport and sequestration of $\mathrm{Al}$ at the vacuole. It is not known in which form OSALS1 transports $\mathrm{Al}$ but it is unlikely transported as its free ion considering that at cytosolic $\mathrm{pH}$ the concentration of $\mathrm{Al}^{3+}$ is very low. It would be interesting to determine if tolerant plants bear homologous genes.

\subsection{Al sequestration at the cell wall}

In tea plants, $\mathrm{Al}$ accumulation is concentrated at the cell walls and is more concentrated in the epidermal cells on the upper leaf surface (Fig. 1E). ${ }^{46}$ This may reflect the apoplasmic transport of Al together with the mass flow of water to the epidermal cells where $\mathrm{Al}$ is deposited when the water evaporates. ${ }^{46 a}$ The high concentration of $\mathrm{Al}$ found on the outer epidermal cell walls supports this view. ${ }^{47}$ One of the advantages of this strategy may be the isolation of $\mathrm{Al}$ from cells with photosynthetic activity. It is not clear if this mechanism can effectively prevent the inhibition of photosynthesis by $\mathrm{Al}$, but tea plants can withstand $\mathrm{Al}$ concentrations that are toxic to many plant species without compromising the rate of photosynthesis. ${ }^{48}$ According to a classification proposed by Wheeler et al. ${ }^{49}$ significant Al tolerance is required to grow normally at this concentration. As mentioned previously, it was suggested that $\mathrm{Al}$ is bound to catechins. ${ }^{14}$ This seemed to be a safe assumption because of the metal-chelating properties of their catechol moieties and their bioavailability (15\% dry weight) is more than sufficient to chelate all Al typically found in tea leaves. However, the accumulation of Al predominantly at the epidermal cell walls makes this hypothesis less likely to be correct, because catechins are mostly found at the vacuoles of mesophyll cells. ${ }^{50}$ Moreover, a catechin-Al complex has never been identified unequivocally. Although the distribution of $\mathrm{Al}$ in tea leaves was studied by low-energy X-ray fluorescence spectromicroscopy, ${ }^{46 b}$ which as an elemental detection technique cannot identify ligands, the high correlation between the localization of $\mathrm{Al}$ and the elements $\mathrm{C}$ and $\mathrm{O}$ suggested that the metal is bound to electronegative carboxylate and hydroxyl groups present in the carbohydrate-rich cell wall.

Light microscopy after staining with pyrocatechol violet was used in M. malabathricum to find that Al predominantly accumulates on the upper cell walls of leaves. ${ }^{13}$ Although this technique is not quantitative, it was sufficient to show that $\mathrm{Al}$ also accumulated to a lesser extent on mesophyll cells. A strong peak attributed to monomeric $\mathrm{Al}$ and several $\mathrm{Al}$-oxalate complexes were detected in fresh leaves by ${ }^{27} \mathrm{Al}-\mathrm{NMR}$, but the location of each $\mathrm{Al}$ species was not determined. This finding contradicts the location of $\mathrm{Al}$ at the cell wall, considering that in an environment rich in hemicellulose and pectin $\mathrm{Al}$ is more likely to bind to carboxylate groups carrying negatively charged oxygen donors. It is possible to detect interactions between the ${ }^{27} \mathrm{Al}$ nucleus and carboxylate groups in plant cell walls, which generate a signal with a broad line width, resonating close to 0 ppm. ${ }^{19}$ Considering that $\mathrm{Al}$ in $M$. malabathricum leaves accumulates predominantly at the cell wall and that the line width of the signal at $0 \mathrm{ppm}$ is much broader than the free $\mathrm{Al}$ signal in the standard solution, Watanabe et al. ${ }^{13}$ may have revealed in their study evidence of $\mathrm{Al}$ binding to carboxylate 
groups in the cell wall. Nevertheless, the broad line width of the signals obtained from ${ }^{27} \mathrm{Al}-\mathrm{NMR}$ makes unequivocal assignment a difficult task. In addition, knowing the accurate $\mathrm{pH}$ of the apoplasm will help to determine the thermodynamic feasibility of this reaction considering that $\mathrm{Al}$ binds to carboxylate groups at $\mathrm{pH} 3.5,{ }^{19}$ lower than the typical apoplasm $\mathrm{pH}$. Al sequestration at the cell wall and vacuole appear to be effective strategies to prevent contact between $\mathrm{Al}$ and essential metabolic processes, although the mechanisms responsible for cellular allocation in Al-tolerant plants are not understood yet.

\subsection{Future prospects for subcellular Al-localization}

In order to gain insight into the formation and localization of $\mathrm{Al}$ complexes and how $\mathrm{Al}$ crosses the plasma membrane and the tonoplast into vacuoles, techniques able to simultaneously deliver spatial distribution and structural information will be required. The lack of sensitivity and structural information provided by NMR and X-ray spectroscopy will continue to pose a significant challenge, so it is more likely that new information will be provided by approaches with inherent sensitivity such as those based on MS. When all known Al-complexes have been consistently characterized and suitable ionization techniques have been developed which maintain these complexes, it may be possible to determine the location of all relevant $\mathrm{Al}$ complexes at the cellular level. Sub- $\mu \mathrm{m}$ resolutions are now achieved routinely and soft ionization techniques are improving, producing higher yields of intact molecular ions. ${ }^{51}$ MS imaging techniques may give more insight into the site-specific speciation and intracellular transport of $\mathrm{Al}$.

\section{The adaptive advantages of aluminium accumulation}

$\mathrm{Al}$ accumulators are so well adapted that in some cases growth is stimulated at optimum $\mathrm{Al}$ concentrations in comparison to plants growing in the absence of $\mathrm{Al}^{32 a, 52}$ The increased performance of plants in the presence of $\mathrm{Al}$ may reflect the amelioration of proton toxicity derived from soil toxicity, improved phosphate uptake or the higher activity of antioxidant enzymes, but this has yet to be established. ${ }^{1 d}$ In M. malabathricum, Al limits the uptake of iron (possibly because of competition for the same transporter proteins) and Al-induced growth is more significant at higher iron concentrations, suggesting that one of the factors behind Al-mediated growth may be the reduction of iron toxicity. ${ }^{53}$

As mentioned above, only a small number of plant species accumulate $\mathrm{Al}$ at high levels in aboveground plant tissues, but a statistical study that correlated the trait of $\mathrm{Al}$ accumulation and seven primitive characters suggests that $\mathrm{Al}$ accumulation is a primitive character. ${ }^{54}$ A more complete phylogenetic study showed that $\mathrm{Al}$ accumulation can be found in basal branches of several plant orders but seems to have been lost in most derived taxa. ${ }^{55}$ Indeed, homologues of the gene encoding a tonoplast-located $\mathrm{Al}$-transporter in rice have been found in several derived plant species, including Physcomitrella patens, a model organism representing initial land plants. ${ }^{5}$

One theory about the phylogenetic distribution of $\mathrm{Al}$ accumulation is that primitive plants encountered Al stress more often than today, making Al tolerance mechanisms a prerequisite for survival, but that the trait was lost subsequently due to its inherent high energetic cost. In some cases the trait may have been conserved for reasons other than adaptation to acidic soils. In $\mathrm{Ni}$ and $\mathrm{Zn}$ hyperaccumulators such as Streptanthus polygaloid and T. caerulescens, accumulation can confer protection against pathogens and herbivores. ${ }^{56}$ It is reasonable to assume that a plant accumulating a large amount of $\mathrm{Al} \mathrm{might}$ be less appealing to herbivores and less susceptible to pathogens, although this hypothesis remains to be tested.

\section{Outlook}

This review compiles data that have improved our understanding of internal Al detoxification from a physiological perspective, i.e. Al is selectively taken into roots at the rhizosphere, forms complexes with organic acids, is transported by the xylem and is sequestered in aboveground tissues. Despite still being elusive, it seems clear that efficient molecular mechanisms are on the basis of the internal detoxification of Al. In rice, the genes responsible for the selective uptake at roots and the sequestration at vacuoles have been recently discovered. ${ }^{4,5}$ However, it remains to be seen if similar mechanisms are operating in tolerant plants. In either case, the diversity of the physiological aspects of $\mathrm{Al}$ internal detoxification suggests that different mechanisms may be anticipated within tolerant plants. Despite the importance of OAs in the internal detoxification of $\mathrm{Al}$, it seems that the regulation of OA synthesis is not necessarily involved in the modulation of $\mathrm{Al}$ tolerance. Instead, whereas high constitutive levels of OAs are required for tolerance, the difference between susceptible and tolerant plants seems to be an efficient mechanism that controls the trafficking of $\mathrm{Al}$ into harmless structures. Undoubtedly, technical improvements will generate a better understanding of the trafficking of $\mathrm{Al}$ even further and will help anticipate the functions of genes involved in Al tolerance mechanisms.

\section{Acknowledgements}

The authors acknowledge support from the Portuguese Foundation for Science and Technology (FCT, project PTDC/AGRAAM/102664/2008 and post-doc grant assigned to T. Grevenstuk SFRH/BPD/73293/2010). The authors wish to thank the reviewers for valuable suggestions and comments.

\section{References}

1 (a) J. Barcelo and C. Poschenrieder, Fast root growth responses, root exudates, and internal detoxification as clues to the mechanisms of aluminium toxicity and resistance: a review, Environ. Exp. Bot., 2002, 48, 75-92, DOI: Pii S0098-8472(02)00013-8; (b) L. V. Kochian, Cellular 
Mechanisms of Aluminum Toxicity and Resistance in Plants, Annu. Rev. Plant Physiol., 1995, 46, 237-260, DOI: 10.1146/Annurev.Arplant.46.1.237; (c) L. V. Kochian, M. A. Pineros and O. A. Hoekenga, The physiology, genetics and molecular biology of plant aluminum resistance and toxicity, Plant Soil, 2005, 274, 175-195, DOI: 10.1007/S11104004-1158-7; (d) J. F. Ma, Syndrome of aluminum toxicity and diversity of aluminum resistance in higher plants, Int. Rev. Cytol., 2007, 264, 225-252, DOI: 10.1016/S0074-7696(07)64005-4; (e) C. Poschenrieder, B. Gunse, I. Corrales and J. Barcelo, A glance into aluminum toxicity and resistance in plants, Sci. Total Environ., 2008, 400, 356-368, DOI: 10.1016/ J.Scitotenv.2008.06.003; $(f)$ S. J. Zheng and J. L. Yang, Target sites of aluminum phytotoxicity, Biol. Plant., 2005, 49, 321-331, DOI: 10.1007/S10535-005-0001-1.

2 H. R. von Uexkull and E. Mutert, Global Extent, Development and Economic-Impact of Acid Soils, Plant Soil, 1995, 171, 1-15.

3 (a) J. F. Ma, P. R. Ryan and E. Delhaize, Aluminium tolerance in plants and the complexing role of organic acids, Trends Plant Sci., 2001, 6, 273-278, DOI: 10.1016/ S1360-1385(01)01961-6; (b) P. R. Ryan and E. Delhaize, The convergent evolution of aluminium resistance in plants exploits a convenient currency, Funct. Plant Biol., 2010, 37, 275-284, DOI: 10.1071/Fp09261.

4 J. X. Xia, N. Yamaji, T. Kasai and J. A. F. Ma, Plasma membrane-localized transporter for aluminum in rice, Proc. Natl. Acad. Sci. U. S. A., 2010, 107, 18381-18385, DOI: 10.1073/Pnas.1004949107.

5 C. F. Huang, N. Yamaji, Z. C. Chen and J. F. Ma, A tonoplastlocalized half-size $\mathrm{ABC}$ transporter is required for internal detoxification of aluminum in rice, Plant J., 2012, 69, 857-867, DOI: 10.1111/J.1365-313x.2011.04837.X.

6 (a) E. Delhaize, J. F. Ma and P. R. Ryan, Transcriptional regulation of aluminium tolerance genes, Trends Plant Sci., 2012, 17, 341-348, DOI: 10.1016/J.Tplants.2012.02.008; (b) P. R. Ryan, E. Delhaize and D. L. Jones, Function and mechanism of organic anion exudation from plant roots, Annu. Rev. Plant Physiol., 2001, 52, 527-560, DOI: 10.1146/ Annurev.Arplant.52.1.527.

7 J. Scancar and R. Milacic, Aluminium speciation in environmental samples: a review, Anal. Bioanal. Chem., 2006, 386, 999-1012, DOI: 10.1007/S00216-006-0422-5.

8 J. F. Ma, S. Hiradate and H. Matsumoto, High aluminum resistance in buckwheat - II. Oxalic acid detoxifies aluminum internally, Plant Physiol., 1998, 117, 753-759, DOI: 10.1104/pp.117.3.753.

9 J. F. Ma and S. Hiradate, Form of aluminium for uptake and translocation in buckwheat (Fagopyrum esculentum Moench), Planta, 2000, 211, 355-360, DOI: 10.1007/ S004250000292.

10 J. F. Ma, S. J. Zheng, H. Matsumoto and S. Hiradate, Detoxifying aluminium with buckwheat, Nature, 1997, 390, 569-570, DOI: 10.1038/37518.

11 (a) A. Morita, O. Yanagisawa, S. Takatsu, S. Maeda and S. Hiradate, Mechanism for the detoxification of aluminum in roots of tea plant (Camellia sinensis (L.) Kuntze), Phytochemistry, 2008, 69, 147-153, DOI: 10.1016/J.Phytochem.2007.06.007; (b) T. Watanabe, S. Misawa and M. Osaki, Aluminum accumulation in the roots of Melastoma malabathricum, an aluminum-accumulating plant, Can. J. Bot., 2005, 83, 1518-1522, DOI: 10.1139/B05-111.

12 (a) A. Morita, H. Horie, Y. Fujii, S. Takatsu, N. Watanabe, A. Yagi and H. Yokota, Chemical forms of aluminum in xylem sap of tea plants (Camellia sinensis L.), Phytochemistry, 2004, 65, 2775-2780, DOI: 10.1016/J.Phytochem.2004.08.043; (b) T. Watanabe and M. Osaki, Influence of aluminum and phosphorus on growth and xylem sap composition in Melastoma malabathricum L, Plant Soil, 2001, 237, 63-70, DOI: 10.1023/A:1013395814958.

13 T. Watanabe, M. Osaki, T. Yoshihara and T. Tadano, Distribution and chemical speciation of aluminum in the Al accumulator plant, Melastoma malabathricum L, Plant Soil, 1998, 201, 165-173, DOI: 10.1023/A:1004341415878.

14 T. Nagata, M. Hayatsu and N. Kosuge, Identification of Aluminum Forms in Tea Leaves by Al-27 NMR, Phytochemistry, 1992, 31, 1215-1218, DOI: 10.1016/00319422(92)80263-E.

15 S. N. Mhatre, R. K. Iyer and P. N. Moorthy, Characterization of Aluminum Complexes in Tea Extract.1. Al-27 NMR-Studies, Magn. Reson. Chem., 1993, 31, 169-175, DOI: 10.1002/ Mrc.1260310203.

16 R. F. Shen, T. Iwashita and J. F. Ma, Form of Al changes with Al concentration in leaves of buckwheat, J. Exp. Bot., 2004, 55, 131-136, DOI: 10.1093/Jxb/Erh016.

17 (a) K. Takeda, R. Kubota and C. Yagioka, Copigments in the Blueing of Sepal Color of Hydrangea macrophylla, Phytochemistry, 1985, 24, 1207-1209, DOI: 10.1016/S00319422(00)81102-4; (b) K. Yoshida, M. Mori and T. Kondo, Blue flower color development by anthocyanins: from chemical structure to cell physiology, Nat. Prod. Rep., 2009, 26, 884-915, DOI: 10.1039/B800165k.

18 J. F. Ma, S. Hiradate, K. Nomoto, T. Iwashita and H. Matsumoto, Internal detoxification mechanism of $\mathrm{Al}$ in hydrangea - Identification of $\mathrm{Al}$ form in the leaves, Plant Physiol., 1997, 113, 1033-1039.

19 H. Y. Xia and G. D. Rayson, Investigation of aluminum binding to a Datura innoxia material using Al-27 NMR, Environ. Sci. Technol., 1998, 32, 2688-2692, DOI: 10.1021/ Es980171s.

20 M. D. Alba, A. I. Becerro, M. A. Castro and A. C. Perdigon, Two-dimensional heteronuclear ${ }^{1} \mathrm{H}^{-27} \mathrm{Al}$ correlated MAS NMR spectra of layered silicates, Chem. Commun., 2001, 249-250, DOI: 10.1039/B008333j.

21 R. N. Collins, Separation of low-molecular mass organic acid-metal complexes by high-performance liquid chromatography, J. Chromatogr., A, 2004, 1059, 1-12, DOI: 10.1016/ J.Chroma.2004.10.026.

22 M. J. Keith-Roach, A review of recent trends in electrospray ionisation-mass spectrometry for the analysis of metalorganic ligand complexes, Anal. Chim. Acta, 2010, 678, 140-148, DOI: 10.1016/J.Aca.2010.08.023. 
23 T. Bantan, R. Milacic, B. Mitrovic and B. Pihlar, Combination of various analytical techniques for speciation of low molecular weight aluminium complexes in plant sap, Fresenius' J. Anal. Chem., 1999, 365, 545-552, DOI: 10.1007/ S002160051520.

24 L. Ouerdane, S. Mari, P. Czernic, M. Lebrun and R. Lobinski, Speciation of non-covalent nickel species in plant tissue extracts by electrospray Q-TOFMS/MS after their isolation by 2D size exclusion-hydrophilic interaction LC (SEC-HILIC) monitored by ICP-MS, J. Anal. At. Spectrom., 2006, 21, 676-683, DOI: 10.1039/B602689c.

25 T. Grevenstuk, P. Flis, L. Ouerdane, R. Lobinski and A. Romano, Identification of the tri-Al tricitrate complex in Plantago almogravensis by hydrophilic interaction LC with parallel ICP-MS and electrospray Orbitrap MS/MS detection, Metallomics, 2013, 5, 1285-1293, DOI: 10.1039/ c3mt00101f.

26 (a) T. L. Feng, P. L. Gurian, M. D. Healy and A. R. Barron, Aluminum Citrate - Isolation and Structural Characterization of a Stable Trinuclear Complex, Inorg. Chem., 1990, 29, 408-411, DOI: 10.1021/Ic00328a013; (b) T. Fukushima, A. K. Sia, B. E. Allred, R. Nichiporuk, Z. R. Zhou, U. N. Andersen and K. N. Raymond, Bacillus cereus iron uptake protein fishes out an unstable ferric citrate trimer, Proc. Natl. Acad. Sci. U. S. A., 2012, 109, 16829-16834, DOI: 10.1073/ Pnas.1210131109; (c) L. O. Ohman, Equilibrium and Structural Studies of Silicon(Iv) and Aluminum(III) in AqueousSolution.17. Stable and Metastable Complexes in the System $\mathrm{H}^{+}-\mathrm{Al}^{3+}$-Citric Acid, Inorg. Chem., 1988, 27, 2565-2570.

27 V. A. Vitorello, F. R. Capaldi and V. A. Stefanuto, Recent advances in aluminum toxicity and resistance in higher plants, Braz. J. Plant Physiol., 2005, 17, 129-143.

28 M. J. Haydon and C. S. Cobbett, Transporters of ligands for essential metal ions in plants, New Phytol., 2007, 174, 499-506, DOI: 10.1111/J.1469-8137.2007.02051.X.

29 B. Klug and W. J. Horst, Spatial characteristics of aluminum uptake and translocation in roots of buckwheat (Fagopyrum esculentum), Physiol. Plant., 2010, 139, 181-191, DOI: 10.1111/J.1399-3054.2010.01355.X.

30 T. B. Polak, R. Milacic, B. Pihlar and B. Mitrovic, The uptake and speciation of various $\mathrm{Al}$ species in the Brassica rapapekinensis, Phytochemistry, 2001, 57, 189-198, DOI: 10.1016/ S0031-9422(01)00055-3.

31 T. Nagata, M. Hayatsu and N. Kosuge, Aluminum Kinetics in the Tea Plant Using ${ }^{27} \mathrm{Al}$ and ${ }^{19} \mathrm{~F}$ NMR, Phytochemistry, 1993, 32, 771-775, DOI: 10.1016/0031-9422(93)85202-3.

32 (a) T. Watanabe, S. Jansen and M. Osaki, The beneficial effect of aluminium and the role of citrate in $\mathrm{Al}$ accumulation in Melastoma malabathricum, New Phytol., 2005, 165, 773-780, DOI: 10.1111/J.1469-8137.2004.01261.X; (b) T. Watanabe and M. Osaki, Role of organic acids in aluminum accumulation and plant growth in Melastoma malabathricum, Tree Physiol., 2002, 22, 785-792.

33 N. Martins, S. Goncalves, P. B. Andrade, P. Valentao and A. Romano, Changes on organic acid secretion and accumulation in Plantago almogravensis Franco and Plantago algarbiensis Samp. under aluminum stress, Plant Sci., 2013, 198, 1-6, DOI: 10.1016/J.Plantsci.2012.09.001.

34 T. C. Fox and M. L. Guerinot, Molecular biology of cation transport in plants, Annu. Rev. Plant Physiol., 1998, 49, 669-696, DOI: 10.1146/Annurev.Arplant.49.1.669.

35 X. C. Hu and G. L. Boyer, Siderophore-mediated aluminum uptake by Bacillus megaterium ATCC 19213, Appl. Environ. Microbiol., 1996, 62, 4044-4048.

36 G. J. Taylor, J. L. McDonald-Stephens, D. B. Hunter, P. M. Bertsch, D. Elmore, Z. Rengel and R. J. Reid, Direct measurement of aluminum uptake and distribution in single cells of Chara corallina, Plant Physiol., 2000, 123, 987-996, DOI: 10.1104/pp.123.3.987.

37 (a) D. Eticha, A. Stass and W. J. Horst, Localization of aluminium in the maize root apex: can morin detect cell wall-bound aluminium?, J. Exp. Bot., 2005, 56, 1351-1357, DOI: 10.1093/Jxb/Eri136; (b) I. R. Silva, T. J. Smyth, D. F. Moxley, T. E. Carter, N. S. Allen and T. W. Rufty, Aluminum accumulation at nuclei of cells in the root tip. Fluorescence detection using lumogallion and confocal laser scanning microscopy, Plant Physiol., 2000, 123, 543-552, DOI: 10.1104/pp.123.2.543; (c) S. J. Zheng, J. F. Ma and H. Matsumoto, High aluminum resistance in buckwheat - I. Al-induced specific secretion of oxalic acid from root tips, Plant Physiol., 1998, 117, 745-751, DOI: 10.1104/pp.117.3.745.

38 W. J. Horst, N. Schmohl, M. Kollmeier, F. Baluska and M. Sivaguru, Does aluminium affect root growth of maize through interaction with the cell wall - plasma membrane cytoskeleton continuum?, Plant Soil, 1999, 215, 163-174, DOI: 10.1023/A:1004439725283.

39 B. Klug, A. Specht and W. J. Horst, Aluminium localization in root tips of the aluminium-accumulating plant species buckwheat (Fagopyrum esculentum Moench), J. Exp. Bot., 2011, 62, 5453-5462, DOI: 10.1093/Jxb/Err222.

40 J. Morrissey, I. R. Baxter, J. Lee, L. T. Li, B. Lahner, N. Grotz, J. Kaplan, D. E. Salt and M. L. Guerinot, The Ferroportin Metal Efflux Proteins Function in Iron and Cobalt Homeostasis in Arabidopsis, Plant Cell, 2009, 21, 3326-3338, DOI: 10.1105/Tpc.109.069401.

$41 \mathrm{H}$. van As, Intact plant MRI for the study of cell water relations, membrane permeability, cell-to-cell and long distance water transport, J. Exp. Bot., 2007, 58, 743-756, DOI: 10.1093/Jxb/Erl157.

42 R. G. Ratcliffe and A. Roscher, Prospects for in vivo NMR methods in xenobiotic research in plants, Biodegradation, 1998, 9, 411-422, DOI: 10.1023/A:1008372107739.

43 M. J. Harbottle, M. D. Mantle, M. L. Johns, R. Van Herwijnen, A. Al-Tabbaa, T. R. Hutchings, A. J. Moffat and S. K. Ouki, Magnetic resonance imaging of the effect of zeolite on lithium uptake in poplar, Environ. Sci. Technol., 2007, 41, 3444-3448, DOI: 10.1021/Es0623111.

44 R. F. Shen, J. F. Ma, M. Kyo and T. Iwashita, Compartmentation of aluminium in leaves of an Al-accumulator, Fagopyrum esculentum Moench, Planta, 2002, 215, 394-398, DOI: 10.1007/S00425-002-0763-Z. 
45 (a) U. Kramer, I. J. Pickering, R. C. Prince, I. Raskin and D. E. Salt, Subcellular localization and speciation of nickel in hyperaccumulator and non-accumulator Thlaspi species, Plant Physiol., 2000, 122, 1343-1353, DOI: 10.1104/pp.122.4.1343; (b) H. Kupper, F. J. Zhao and S. P. McGrath, Cellular compartmentation of zinc in leaves of the hyperaccumulator Thlaspi caerulescens, Plant Physiol., 1999, 119, 305-311, DOI: 10.1104/ pp.119.1.305.

46 (a) H. Matsumoto, E. Hirasawa, S. Morimura and E. Takahashi, Localization of Aluminum in Tea Leaves, Plant Cell Physiol., 1976, 17, 627-631; (b) R. Tolra, K. Vogel-Mikus, R. Hajiboland, P. Kump, P. Pongrac, B. Kaulich, A. Gianoncelli, V. Babin, J. Barcelo, M. Regvar and C. Poschenrieder, Localization of aluminium in tea (Camellia sinensis) leaves using low energy X-ray fluorescence spectro-microscopy, J. Plant Res., 2011, 124, 165-172, DOI: $10.1007 /$ S10265-010-0344-3.

47 H. P. Carr, E. Lombi, H. Kupper, S. P. McGrath and M. H. Wong, Accumulation and distribution of aluminium and other elements in tea (Camellia sinensis) leaves, Agronomie, 2003, 23, 705-710, DOI: 10.1051/Agro:2003045.

48 M. Mukhopadyay, P. Bantawa, A. Das, B. Sarkar, B. Bera, P. Ghosh and T. K. Mondal, Changes of growth, photosynthesis and alteration of leaf antioxidative defence system of tea [Camellia sinensis (L.) O. Kuntze] seedlings under aluminum stress, Biometals, 2012, 25, 1141-1154, DOI: 10.1007/S10534-012-9576-0.

49 D. M. Wheeler, D. C. Edmeades, R. A. Christie and R. Gardner, Effect of Aluminum on the Growth of 34 Plant-Species - a Summary of Results Obtained in Low Ionic-Strength Solution Culture, Plant Soil, 1992, 146, 61-66, DOI: 10.1007/Bf00011996.

50 T. Suzuki, N. Yamazaki, Y. Sada, I. Oguni and Y. Moriyasu, Tissue distribution and intracellular localization of catechins in tea leaves, Biosci., Biotechnol., Biochem., 2003, 67, 2683-2686, DOI: 10.1271/Bbb.67.2683.
51 L. A. McDonnell, R. M. A. Heeren, R. P. J. de Lange and I. W. Fletcher, Higher sensitivity secondary ion mass spectrometry of biological molecules for high resolution, chemically specific imaging, J. Am. Soc. Mass Spectrom., 2006, 17, 1195-1202, DOI: 10.1016/J.Jasms.2006.05.003.

52 (a) F. Ghanati, A. Morita and H. Yokota, Effects of aluminum on the growth of tea plant and activation of antioxidant system, Plant Soil, 2005, 276, 133-141, DOI: 10.1007/ S11104-005-3697-Y; (b) S. Konishi, S. Miyamoto and T. Taki, Stimulatory Effects of Aluminum on Tea Plants Grown under Low and High Phosphorus Supply, Soil Sci. Plant Nutr., 1985, 31, 361-368; (c) M. Osaki, T. Watanabe and T. Tadano, Beneficial effect of aluminum on growth of plants adapted to low pH soils, Soil Sci. Plant Nutr., 1997, 43, 551-563.

53 T. Watanabe, S. Jansen and M. Osaki, Al-Fe interactions and growth enhancement in Melastoma malabathricum and Miscanthus sinensis dominating acid sulphate soils, Plant, Cell Environ., 2006, 29, 2124-2132, DOI: 10.1111/J.13653040.2006.01586.X.

54 E. M. Chenery and K. R. Sporne, Note on Evolutionary Status of Aluminum Accumulators among Dicotyledons, New Phytol., 1976, 76, 551-554, DOI: 10.1111/J.1469-8137.1976.Tb01491.X.

55 S. Jansen, M. R. Broadley, E. Robbrecht and E. Smets, Aluminum hyperaccumulation in angiosperms: A review of its phylogenetic significance, Bot. Rev., 2002, 68, 235-269, DOI: 10.1663/0006-8101(2002)068[0235:Ahiaar]2.0.Co;2.

56 (a) R. S. Boyd, J. J. Shaw and S. N. Martens, Nickel Hyperaccumulation Defends Streptanthus Polygaloides (Brassicaceae) against Pathogens, Am. J. Bot., 1994, 81, 294-300, DOI: 10.2307/2445455; (b) A. J. Pollard and A. J. M. Baker, Deterrence of herbivory by zinc hyperaccumulation in Thlaspi caerulescens (Brassicaceae), New Phytol., 1997, 135, 655-658, DOI: 10.1046/J.1469-8137.1997.00689.X. 